\title{
Recommendations for standards of physiotherapy care following complete traumatic paraplegia in India
}

\author{
Nalina Gupta ${ }^{1,2}$ \\ Received: 6 June 2019 / Revised: 6 February 2020 / Accepted: 6 February 2020 \\ (c) The Author(s), under exclusive licence to International Spinal Cord Society 2020
}

\begin{abstract}
Study design Qualitative study.

Objectives To formulate recommendations for standards of physiotherapy care for people with complete traumatic paraplegia in India using a Delphi methodology.

Setting India.

Methods Twenty-three physiotherapy experts were invited to participate in an online consensus process. Fourteen $(n=14)$ of 23 physiotherapy experts from India accepted an invitation to participate in an online consensus development exercise (Response rate-60.86\%). Four rounds of consensus meetings were conducted which involved posting the quotations from a previous study on expectations of people with paraplegia to obtain perceptions of physiotherapy experts in round 1, retrieving codes/code groups from round 1, posting these code groups in rounds 2 and 3 for experts' agreement/disagreement, the preparation of the draft of recommendations, and posting it in round 4 for experts' opinion. Data were analyzed using descriptive statistics and ATLASti software for qualitative data analysis.

Result Recommendations for physiotherapy care for persons with complete traumatic paraplegia in India are presented. Conclusions Education to patients and/or caregivers regarding care post injury is one of the important recommendations by physiotherapy experts. It is emphasized that the subjective assessment of the patients, including their needs and preferences, is equally important as that of their objective assessment. Physiotherapy students and practicing physiotherapists must also enhance their knowledge to provide optimal physiotherapy care to people with paraplegia.
\end{abstract}

\section{Introduction}

Demographics of spinal injuries in India differ from those of developed countries, with regard to gender, type, and mode of injury. Road traffic accidents and falls from the height are the major causes of spinal cord injury (SCI) in India [1]. Due to a lack of SCI centers in India [1], a person with acute SCI is taken to any of the hospitals available in the vicinity and there is often a delay in comprehensive management. Patients are often discharged once their vertebral lesion is managed and advised to continue exercises at home rather than being referred to a definitive spinal or rehabilitation

Nalina Gupta

nals235@yahoo.co.in

School of Physiotherapy, R K University, Rajkot, Gujarat, India

2 College of Physiotherapy, Sumandeep Vidyapeeth, An InstitutionDeemed-to-be University, Vadodara, Gujarat, India center [2]. The possible reasons for their early hospital discharge include nonavailability of beds, financial constraints, lack of rehabilitation facilities, and lack of awareness about the importance of rehabilitation [2]. Subsequently, individuals with SCI are predisposed to complexities such as pressure sores, contractures, and deformities as well as psychosocial issues that will negatively influence their overall rehabilitation outcome [2].

Physiotherapy is one of the key components of SCI rehabilitation which involves interventions related to domains of body structure and function, activity limitation, and participation [3, 4]. Physiotherapy should begin in the early acute stage and exercises should continue on lifelong basis. To provide optimal care for persons with SCI, physiotherapists need technical knowledge regarding the patients' condition and treatment in addition to an understanding of the consumers' expectations [5]. Thus, it is important to understand the lived experiences of people with paraplegia/SCI [6].

In a previous study, online focus group interviews of people with paraplegia were conducted to understand their 
expectations and experiences. Interviews were conducted in either Hindi or English until data saturation. Recorded interviews were transcribed into text and data were analyzed by using ATLASti software for qualitative data analysis. The analysis involved coding the document and grouping the codes into code groups. Various code groups that emerged were related to a lack of knowledge in the general public regarding SCI, inadequate care at the accident site, lack of education regarding SCI provided to the patients and families in the hospital, inadequate rehabilitation/physiotherapy facilities in the hospital, lack of guidance or referral for physiotherapy after discharge, and lack of facilities for exercises/relaxation for people with paraplegia in education and employment centers [7].

Despite the great need for services, there are no freely available protocols or standards for physiotherapy care for persons with paraplegia in India. Thus, this study aimed to obtain perceptions of physiotherapy experts regarding expectations/experiences of people with paraplegia and to formulate recommendations for standards of physiotherapy care for people with paraplegia in India.

\section{Method}

This qualitative study was approved by the ethical committee through the Central Drugs Standard Control Organization and registered in the Clinical trial registry of India. We certify that all applicable institutional and governmental regulations concerning the ethical use of human volunteers were followed during this research. A modified Delphi methodology was used to bring consensus. Multiple viewpoints were obtained and refined through various rounds of data collection from the respondents [8].

Twenty-three physiotherapy experts with a minimum of 5 years' experience in SCI/Neurological Rehabilitation were sent an invitation to participate. Fifteen individuals responded (response rate $=65.2 \%$ ), and fourteen agreed to participate in the study (response rate $=60.86 \%$ ). The demographic details of the participants are shown in Table 1. Four rounds of consensus building using English were then conducted using Google forms.

In round 1, quotations based on the previously described emerged code groups from online focus group interviews of people with paraplegia [5] were sent to the participants, as shown in Table 2. Once the interview was over, the interview was transcribed into a word document in the English language [3]. Once the comments of physiotherapy experts were received in round 1, data were analyzed using ATLASti software for qualitative data analysis. Nineteen codes were retrieved that were grouped into four code groups. These four code groups were related to awareness, knowledge, and education regarding paraplegia, functional
Table 1 Demographics of physiotherapy experts $(n=14)$.

\begin{tabular}{|c|c|}
\hline Variables & Number $(n)$ \\
\hline \multicolumn{2}{|l|}{ Age } \\
\hline $25-30$ years & 2 \\
\hline $31-40$ years & 5 \\
\hline $41-50$ years & 3 \\
\hline $51-60$ years & 3 \\
\hline $61-70$ years & 1 \\
\hline \multicolumn{2}{|l|}{ Gender } \\
\hline Male & 7 \\
\hline Female & 7 \\
\hline \multicolumn{2}{|l|}{ Qualification } \\
\hline MPT/MSc PT & 8 \\
\hline Ph.D. & 6 \\
\hline \multicolumn{2}{|l|}{ Total experience } \\
\hline $5-10$ years & 3 \\
\hline $11-15$ years & 4 \\
\hline $21-25$ years & 2 \\
\hline 26-30 years & 3 \\
\hline $31-35$ years & 1 \\
\hline $36-40$ years & 1 \\
\hline \multicolumn{2}{|l|}{ Experience with SCI rehabilitation } \\
\hline $5-10$ years & 4 \\
\hline $11-15$ years & 4 \\
\hline $21-25$ years & 2 \\
\hline 26-30 years & 2 \\
\hline $31-35$ years & 1 \\
\hline $36-40$ years & 1 \\
\hline \multicolumn{2}{|l|}{ Designation } \\
\hline Physiotherapist & 3 \\
\hline Senior physiotherapist & 1 \\
\hline Sr. lecturer/associate professor & 6 \\
\hline Professor & 4 \\
\hline
\end{tabular}

goals, mobility skills, and physiotherapy in various contexts and paraplegia.

In round 2, code groups related to awareness, knowledge, and education regarding paraplegia, and functional goals were posted for the participants' review. Subsequently in round 3, code groups related to mobility skills and physiotherapy in various contexts were posted to the experts for their opinion and agreement/disagreement. Forty-five codes were retrieved from round 2 and grouped into five code groups. Twenty-one codes were retrieved from round 3 and grouped into two code groups. Codes with code groups of rounds 1, 2, and 3 are as shown in Tables 3, 4, and 5. In round 4 , a compiled report of 15 recommendations based on rounds 2 and 3 was sent to all the participants for their agreement/disagreement. Recommendations were accepted if $90-100 \%$ of the experts agreed to it. Thirteen experts 
Table 2 Patients' quotations retrieved from online focus group interviews sent in round 1 for physiotherapy expert's opinion.

S.No. Patients' quotations

1. "When I had this accident, I expected that I will be able to walk in 2-4 or 6 months." "I expected that I will get recover in a month or two and shall start walking on my feet." "I thought I will start walking after the operation but that did not happen." "I thought I will be able to bend my legs."

2. "Physiotherapy and rehabilitation for me is that they will make us stand and send us back home." "People have this mindset that they should be able to walk like before but that does not happen."

3. "We used to have meeting with doctors and staff and I used to tell them that you make me do whatever but make me stand on my feet. They gave me AFOs, gaiters, and made me stand within the parallel bar and then made me walk outside with the help of a walker. Then, they said, see you are walking. I used to tell them to make me walk without AFOs and gaiters. I felt they are just making money. I feel that they have done cheating."

4. "Due to lack of knowledge, our expectations were not realistic/ practical."

5. "My friend used to come and tell me about shifting and movement and then I practiced." "I did not need to learn these skills, it just started automatically."

6. "They were giving me options but I did not like that much. Also I felt that this will occupy more time and I won't have much time for physiotherapy. So, I opted to resign." "If I go for a job, I have to leave exercises. That's why I am not working."

7. "Physiotherapy center is little far from here, around $1.5-2 \mathrm{~km}$. After coming back from classes, we cannot go there as we are really tired. If we get it in a hostel, we can do that. Otherwise we cannot do that." "We don't get time because of classes. We are out from 8am and come back at 6-7 pm. Then, we don't have energy to get exercises done."

8. "I did not get good first treatment as it is not that known here. They made me lie on bed for one month and I had pressure sores. They did not operate me."

9. "My expectation from physiotherapy is to make me capable enough to carry out my daily tasks."

10. "Wheel-chair skills must be taught at most of the centers and it is important if they are taught by a wheel-chair user."

11. "Physiotherapist should know what to bend, how to bend and how much to bend. I have met many students who do not know how to shift patients from bed to wheel-chair. Very few people know about it. They should know how much pressure to be given. $30 \%$ students don't know about it while $70 \%$ know about it."

12. "I have changed many physiotherapists. They used to behave as if they have not seen such cases. I had to tell them that I was made to do like this in a specialized center, so you should do this way only."

13. "There is no guidance, nothing over here for sports guidance. Rehab centers are here but no specialized centers for SCI."

14. "I come from a place where there is no scope of physiotherapy. But physiotherapist has done a lot for me and today I am independent for most of the things."

15. "I have a good wheel-chair, so I can do most of the things. But others don't have, so they cannot do it. So, availability of a good wheel-chair is also a main thing."

16. "My wheel-chair is of old type. There is no folding system. Arm-rests cannot be taken out. That's why there is a problem."

17. "Either your research should do something or by God's grace, I should be able to walk."

18. "May be while doing physiotherapy, some nerves get pressed and we may start walking again. So, we must get physiotherapy done."

19. "I get jerks in my spine. I think if it gets improved with physiotherapy, it will be good."

20. "Initially, I was taking physiotherapy twice at home. I felt some improvement will be there. I may be able to move from one place to another. But I did not have any improvement and my tightness has increased."

21. "I was getting pain in my legs, but if I have no sensation, then how was I getting pain? I feel that my sensation will come but I don't know when it will come."

22. "I am maintaining my ankle joints as may be my spine starts working one day."

23. "I used to think that specialized centers will have machines like robotics because of which cells get activated. Those equipments must be used. We do everything manual."

24. "There should be a way to measure our improvement. They just ask your ASIA level. I know my feet are not working but I need to know how much my strength has been improved."

25. "Patients like us should not tell physiotherapists what to be done; they must do what physiotherapists tell them to do. We learn from specialized centers but our body may demand some different exercises now. Let physiotherapist do his/her work."

26. "I was staying in a village and used to do spring Wala exercise. Nobody used to make me do hard exercises."

27. "Life gets spoilt for the one who lives in a village."

28. "I was sent to a rehabilitation center after four days and I was given dumbbell of $5 \mathrm{Kg}$. I started my exercises from day 5 . I had a gun shot injury."

29. "I have learnt car-shifting at the specialized center as well as have seen it on the internet but I have devised my own way and I am more comfortable with that."

30. "I never learnt shifting from the shifting board because it will become a habit. I need to do it by myself. If I get injured by using shifting board, bed sore will be a problem. Then, I will have to get admitted for plastic surgery and spend some 3-4 lacs. So, I refused to take any sort of help."

agreed to all the 15 recommendations, and one expert suggested some additions. In all the rounds, 4-5 reminders were sent to get all the responses. The flow chart for the methodology is shown in Fig. 1.

\section{Results}

The final draft of recommendations by participants for physiotherapy care for persons with paraplegia in India is as shown in Table 6.

\section{Discussion}

Experiences/expectations of the people with paraplegia were analyzed by physiotherapy experts. Based upon the consumers' inputs, the therapists recommended areas to address to improve the standards of physiotherapy care for people with paraplegia in India.

"To be able to stand and walk again" and "being functionally independent" were the most common expectations individuals with paraplegia reported, irrespective of their level of lesion and severity of the injury [3]. Most of the time, these 
Table 3 Code groups retrieved after the first round of consensus.

\begin{tabular}{|c|c|c|}
\hline S.No. & Codes & Code groups \\
\hline 1. & $\begin{array}{l}\text { Advanced Technology } \\
\text { Education to physiotherapy } \\
\text { students regarding paraplegia/ } \\
\text { SCI } \\
\text { Education to the patient } \\
\text { regarding future outcome/ } \\
\text { recovery/prognosis } \\
\text { Interaction with other patients } \\
\text { with SCI } \\
\text { Knowledge of Physiotherapists } \\
\text { Learning the skill to facilitate } \\
\text { communication with the patient } \\
\text { Model of Rehabilitation } \\
\text { Motor recovery after SCI } \\
\text { Patients' awareness regarding } \\
\text { recovery and prognosis } \\
\text { Physiotherapy and students with } \\
\text { paraplegia } \\
\text { Recovery signs }\end{array}$ & $\begin{array}{l}\text { Education regarding } \\
\text { paraplegia }\end{array}$ \\
\hline 2. & $\begin{array}{l}\text { Assessment tool Functional } \\
\text { goals after SCI Team approach }\end{array}$ & $\begin{array}{l}\text { Functional goals after } \\
\text { paraplegia }\end{array}$ \\
\hline 3. & $\begin{array}{l}\text { Employment } \\
\text { Physiotherapy and students with } \\
\text { paraplegia }\end{array}$ & $\begin{array}{l}\text { Paraplegia and } \\
\text { physiotherapy in various } \\
\text { contexts }\end{array}$ \\
\hline 4. & $\begin{array}{l}\text { Transfer skills } \\
\text { Wheel-chair } \\
\text { Wheel-chair skills }\end{array}$ & Skills \\
\hline
\end{tabular}

expectations were not realistic/practical due to lack of knowledge and education regarding their recovery and prognosis [3]. We believe these expectations are based on cultural beliefs, education, awareness, socioeconomic status, and each patient's understanding of his/her problem. Unmet expectations lead to dissatisfaction, disappointment, anger, and noncompliance/suboptimal compliance to the treatment and poor outcome [9]. In less developed countries like India, timely treatment and education of persons with SCI is often unavailable due to a lack of specialized centers, untrained personnel, lack of equipment, and lack of a multidisciplinary approach [10]. It is also challenging to counsel individuals with SCI regarding the nature of the injury and its prognosis due to cultural issues in developing countries. Initially, individuals with SCI are reluctant to accept their limitations and try to seek spiritual and faith healers [11]. Thus, it becomes very important to be explicit/clear in providing realistic information to the patient regarding his/her recovery, prognosis, and post discharge rehabilitation. Special emphasis on education to the patients and their caregivers must be given. Patients must be encouraged to interact with other individuals who have experience living with paraplegia as peer interaction may provide them with more insight.

Physiotherapy must be started in the initial phase of rehabilitation. The physiotherapy role revolves around the
Table 4 Codes and code groups after round 2 of consensus.

\begin{tabular}{|c|c|c|}
\hline S.No. & Codes & Code groups \\
\hline 1. & $\begin{array}{l}\text { Environmental factors for } \\
\text { functional goals } \\
\text { In India, we have to consider } \\
\text { practical realism } \\
\text { ISNSCI, SCIM } \\
\text { MAS } \\
\text { QoL, ICF core-sets } \\
\text { Using ICF core-sets as a } \\
\text { guiding tool } \\
\text { WISCI, WST-patient and } \\
\text { caregiver, PUS }\end{array}$ & Assessment tools \\
\hline 2. & $\begin{array}{l}\text { e-learning courses } \\
\text { experts to travel } \\
\text { fellowships } \\
\text { own efforts to learn and } \\
\text { recommend } \\
\text { prepare educational modules } \\
\text { reading research evidences } \\
\text { seminars short video clips, talks } \\
\text { Supervised by seniors } \\
\text { Trainings } \\
\text { visits }\end{array}$ & $\begin{array}{l}\text { Education of } \\
\text { Physiotherapy students }\end{array}$ \\
\hline 3. & $\begin{array}{l}\text { Gradual education } \\
\text { Knowledge of outcome } \\
\text { Multi-disciplinary education } \\
\text { Regular Interactive sessions } \\
\text { Restorative and compensatory } \\
\text { methods } \\
\text { Right from the day one- } \\
\text { education } \\
\text { Team Leader } \\
\text { Timely advise and } \\
\text { implementation of assistive } \\
\text { devices } \\
\text { When therapist is sure for } \\
\text { education }\end{array}$ & Education to the patient \\
\hline
\end{tabular}

4. EQ-Ambulation Expectation questionnaire

EQ-distracting

EQ-Job

EQ-no need

EQ-personality type

EQ-phase wise

EQ-secondary complications

EQ-sexual life

EQ-ADLs

EQ-personal information

Open ended questionnaire

5. Connectivity issue

One to one counseling

Tele-physiotherapy for

maintenance

Tele PT-later stages

Tele PT-long term

Tele PT-with specialized centers

Tele-physiotherapy

prevention of secondary complications, bed mobility, transfers, wheelchair mobility, and ambulation with the help of orthosis/aid. Many times, patients are not trained in these 
Table 5 Codes and code groups after round 3 of consensus.

\begin{tabular}{lll}
\hline S.No. & Codes & Code group \\
\hline 1. & $\begin{array}{l}\text { Appraised the importance of continuing } \\
\text { physiotherapy }\end{array}$ & Context specific physiotherapy \\
& Context specific rehab is a good idea & \\
Educational institutes & \\
& Environment at work-place and institutes & \\
& Flexible duty time & \\
& Institutes must allow physical activity \\
& Principal/Director/CEO/Vice-chancellor must & \\
be sensitized & \\
Care & Guidelines for physiotherapy care for persons \\
Comprehensive evaluation & with paraplegia \\
Contextual factors & \\
Currently no guidelines & \\
Early transfer activities & \\
ICF core-sets & \\
International guidelines & \\
Reference articles for guideline & \\
Guidelines must address & \\
No fixed guideline & \\
Mobility skills & \\
Wheel-chair service training & \\
Without any specific guideline & \\
WHO guidelines &
\end{tabular}

Fig. 1 Flow chart of the methodology adopted to develop recommendations for standards of physiotherapy care for traumatic paraplegia in India. The final draft of the recommendations for physiotherapy care for persons with paraplegia was prepared after four rounds of consensus with experts. Step 1: Invitation to Experts. Step 2: Consensus Round 1. Step 3: Consensus Rounds 2 \& 3. Step 4: Consensus Round 4. Step 5: Preparation for final draft. Arrow symbol used is showing the sequence of methodology.

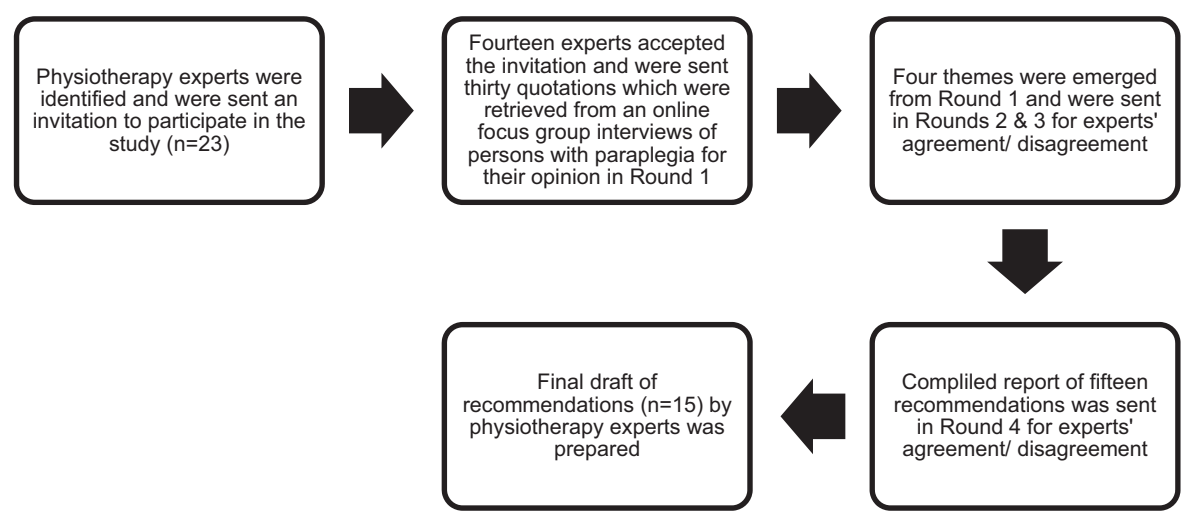

skills due to a lack of access to specialized centers or a lack of experienced professionals in the local hospitals. In such cases, persons with SCI may learn these skills by themselves or from a friend with SCI [12]. Physiotherapists working in local hospitals/centers may also have inadequate knowledge in caring of persons with SCIs. Lack of trained manpower is one of the major challenges in India [13] and could contribute to an inability to meet or redirect patients' expectations. Some of the methods to mitigate this would be through organizing workshops or by way of e-learning courses.

In India, there are very few centers that are specialized in SCI rehabilitation. Patients receive care at these centers and learn basic skills during their inpatient stay. In contrast, patients may be treated in nonspecialized centers in rural areas and develop secondary complications $[1,2,13]$. Thus, it is recommended that all medical workers, even those at the Primary Health Centers, are educated about SCI and its care. If primary providers are unable to manage the patient, they should refer the patient to a specialized hospital. In addition, with newer technologies, such as telehealth, persons with SCIs in rural areas may also receive access to proper medical care and rehabilitation [14].

\section{Conclusion}

Education to the persons with SCI and caregivers regarding care post SCI is one of the important recommendations by physiotherapy experts. Subjective assessment of the patient, including their needs and preferences, is equally important as objective assessment. Physiotherapy students and practicing 
Table 6 Recommendation for standards of physiotherapy care for persons with paraplegia in India.
S.No. Recommendations by physiotherapy experts in India

1. Knowledge regarding physiotherapy care of persons with paraplegia could be enhanced using elearning resources, trainings, experts' visits, workshops, seminars, fellowships, and massive online courses (MOOCs).

2. Practical training should be encouraged in a spinal cord injury (SCI) specialized center for physiotherapy students if this type of care is not available at their center.

3. It is very important for physiotherapy students or physiotherapists to consult their faculty/senior physiotherapists while dealing with persons with paraplegia in the center/at home. They must also try to update themselves with research evidence.

4. Education to persons with paraplegia and their families/caregivers must be performed as soon as the therapist is sure of their recovery/prognosis and they are ready to listen. They must be educated about the restorative and compensatory methods of functional recovery. They must also be educated regarding prevention and treatment of secondary complications. Regular interactive sessions with patients and their families/caregivers will help develop rapport and understanding of their expectations.

5. An open ended questionnaire regarding expectations of persons with paraplegia could be used. This questionnaire should be administered once patients have been educated regarding SCI.

6. It is important to give timely advice to individuals with SCI to avoid the development of false hopes due to lack of adequate knowledge.

7. Interaction with an individual with paraplegia /SCI who has already been rehabilitated, must be organized or encouraged as this will give more insight to the patient.

8. Physiotherapists must use assessment tools for persons with paraplegia such as Asia Impairment Scale (AIS)/International Standards for Neurological Classification of Spinal Cord Injury (ISNCSCI) [15], Walking Index for Spinal Cord Injury (WISCI) [16], Wheelchair Skill Test (WST) [17], Pressure Ulcer Scale for Healing (PUSH score) [18], and International Classification of Functioning, Disability and Health (ICF) core sets [19, 20].

9. ICF core sets can be used for assessment as well as for setting goals (as a guiding tool) to decide what areas need to be worked on.

10. Physiotherapists must have knowledge of various organizations providing financial assistance to assistive devices as well as they must also be trained in wheelchair skills. Customization of a wheelchair is an important area.

11. Assistive devices required for rehabilitation of persons with paraplegia must be implemented as early as possible, rather than spending more time on impairments.

12. Physiotherapists can use guidelines proposed by WHO in collaboration with CMC, Vellore or that of international societies, or by reading research evidence [11].

13. Physiotherapists can include tele-physiotherapy for persons with paraplegia in chronic/later stages for follow up, to avoid secondary complications as well as for having interaction with specialized center.

14. Higher authorities at workplace and educational institutes must be sensitized toward persons with paraplegia. Persons with SCI must be given the option of flexible working hours so that they could get a time for their exercises. They may also be benefitted by tele-physiotherapy.

15. In India, we need to be realistic rather than idealistic. We may not be able to follow specific guidelines due to many factors such as economic constraints, lack of infrastructure, or societal attitudes. Thus, it is important to have goals that are achievable in a realistic setting, e.g., customization of a wheelchair may not be possible due to lack of resources or economic constraints, but that does not restrain patients from learning transfers. Goal setting must also be realistic considering the rural and urban population. physiotherapists must enhance their knowledge to provide optimal physiotherapy care to people with paraplegia.

Acknowledgements I would like to acknowledge Dr Kavitha Raja, Principal, JSS College of Physiotherapy, Mysore for guiding me in this study and Dr Priyanshu Rathod, Director, School of Physiotherapy, R $\mathrm{K}$ University for his constant support and encouragement.

Contributors (panel of physiotherapy experts) Dr (Prof.) Lata Parmar, PT, Ph.D., Principal, College of Physiotherapy, Sumandeep
Vidyapeeth, Vadodara, Gujarat, India. Dr Raju K. Parasher, PT, EdD, Director/Principal, Amar Jyoti Institute of Physiotherapy, Karkardooma, Delhi, India. Mrs Vimal Telang, Lecturer (Physiotherapy), All India Institute of Physical Medicine and Rehabilitation (AIIPMR), Mumbai, Maharashtra. Dr Yagna Shukla, PT, Ph. D., Government Physiotherapy College and Government Spine Institute, Civil Hospital, Ahmedabad. Andrew Babu, Senior Reader \& Head of Physiotherapy Unit, PMR Department, CMC Hospital, Vellore, Tamilnadu, India. Dr Chitra Kataria, Head of Rehabilitation Services, Indian Spinal Injuries Centre, Delhi, India. Prof. R. Harihara Prakash, Principal \& Head, K.M. Patel Institute of 
Physiotherapy, Karamsad, Anand, Gujarat, India. John Solomon, PT, Ph.D., Associate Professor, Department of Physiotherapy, School of Allied Health Sciences, Manipal University, Manipal. Karthik Babu, PT, Ph.D. Associate Professor, Department of Physiotherapy, School of Allied Health Sciences, Manipal University, Manipal. Harpreet Singh Sachdeva, Senior Physiotherapist, AlIMS, Delhi, India. Dr Sayli Thuse, Professor and HOD, Neurophysiotherapy, MAEER's Physiotherapy College, Talegaon Dabhade, Pune, Maharashtra, India. Dr Ashok Trivedi, Physiotherapist, Jaya Rehabilitation Centre, Bidada, Kutch, Gujarat, India. Dr Snehal K. Patel, Physiotherapist, Paraplegic Foundation, Mumbai, Maharashtra, India. Dr Uthra Mohan, Physiotherapist, Paraplegic Foundation, Mumbai, Maharashtra, India.

\section{Compliance with ethical standards}

Conflict of interest The author declares that she has no conflict of interest.

Publisher's note Springer Nature remains neutral with regard to jurisdictional claims in published maps and institutional affiliations.

\section{References}

1. Chhabra HS, Arora M. Demographic profile of traumatic spinal cord injuries admitted at Indian Spinal Injuries Centre with special emphasis on mode of injury: a retrospective study. Spinal Cord. 2012;50:745-54.

2. Chhabra HS, Arora M. Neglected traumatic spinal cord injuries: causes, consequences and outcomes in an Indian setting. Spinal Cord. 2013;51:238-44.

3. Schroeder ST, LaBarbera J, McDowell S, Zanca JM, Natale A, Mumma S, et al. The SCIRehab project: treatment time spent in SCI rehabilitation. Physical therapy treatment time during inpatient spinal cord injury rehabilitation. J Spinal Cord Med. 2011;34:149-61.

4. Van Langeveld SA, Post MW, Asbeck SWV, Gregory M, Halvorsen A, Rijken $\mathrm{H}$, et al. Comparing content of therapy for people with a spinal cord injury in post-acute in-patient rehabilitation in Australia, Norway and Netherland. Phys Ther. 2011;91:210-24.

5. Trylinska-Tekielska E. Questionnaire of expectation patientphysiotherapist (QEPP). Adv Pall Med. 2012;11:56-61.

6. Harvey LA, Adams R, Chu J, Batty J, Barratt D. A comparison of patients' and physiotherapists' expectations about walking post spinal cord injury: a longitudinal cohort study. Spinal Cord. 2012;50:548-52.

7. Gupta N, Raja K. Expectations of persons with paraplegia regarding their care in India-a qualitative study. Spinal Cord Ser Cases. 2017;3:17042. https://doi.org/10.1038/scsandc. 2017.42.

8. Okoli C, Pawlowski SD. The Delphi method as a research tool: an example, design considerations and applications. Inf Manag. 2004;42:15-29.

9. Lateef F. Patient expectation and the paradigm shift of care in emergency medicine. J Emerg Trauma Shock. 2011;4:163-7.

10. Chhabra HS, Batra S. Spinal cord injury and its impact on the patient, family and the society. Int J Recent Surg Med Sci. 2016;2:1-4.

11. Harvey LA. Physiotherapy rehabilitation for people with spinal cord injuries. J Physiother. 2016;62:4-11.

12. Gupta N, Raja K. Physiotherapy care for adults with paraplegia due to traumatic causes: a review. Disabil CBR Incl Dev. 2016;27. https://doi.org/10.5463/DCID.v27i3.512.

13. Chhabra HS, Sharma S, Arora M. Challenges in comprehensive management of spinal cord injury in India and in the Asian Spinal Cord network region: findings of a survey of experts, patients and consumers. Spinal Cord. 2018;56:71-7.

14. Khanna M, Gowda GS, Bagevadi VI, Gupta A, Kulkarni K, Shyam RPS, et al. Feasibility and Utility of Tele-Neurorehabilitation Service in India: Experience from a Quaternary Center. J Neurosci Rural Pr. 2018;9:541-4.

15. International Standards for Neurological Classification of SCI (ISNCSCI) Worksheet. 2019. https://asia-spinalinjury.org/interna tional-standards-neurological-classification-sci-isncsci-worksheet/.

16. Ditunno JF Jr, Ditunno PL, Scivoletto G, Patrick M, Dijkers M, Barbeau $\mathrm{H}$, et al. The Walking Index for Spinal Cord Injury (WISCI/WISCI II): nature, metric properties, use and misuse. Spinal Cord. 2013;51:346-55.

17. Wheelchair Skill Test. 2017. https://scireproject.com/outcome-mea sures/outcome-measure-tool/wheelchair-skills-test-wst/\#146798389 4177-6b9fb7a3-f550.

18. Pressure Ulcer Scale for Healing. 2013. https://www.sralab.org/ rehabilitation-measures/pressure-ulcer-scale-healing.

19. Kirchberger I, Cieza A, Biering-Sørensen F, Baumberger M, Charlifue S, Post MW, et al. ICF core sets for individuals with spinal cord injury in the early post-acute context. Spinal Cord. 2010;48:297-304.

20. Cieza A, Kirchberger I, Biering-Sørensen F, Baumberger M, Charlifue S, Post MW, et al. ICF core sets for individuals with spinal cord injury in the long-term context. Spinal Cord. 2010;48:305-12. 